\title{
PERFORMANCE EVALUATION OF HOT SPOT EXTRACTION AND QUANTIFICATION ALGORITHMS FOR ON-LINE WELD MONITORING FROM WELD THERMOGRAPHS
}

\author{
N. M. Nandhitha \\ Senior Lecturer, Dept. of Electronic Science \\ Sathyabama University, Jeppiaar Nagar \\ Old Mamallapuram Road, Chennai 119 \\ nandhi_n_m@yahoo.co.in \\ B. Sheela Rani \\ Prof. \& Head, Dept. of EIE \\ Sathyabama University, Jeppiaar Nagar, \\ Old Mamallapuram Road, Chennai 119 \\ Sri_kavi_sheela@yahoo.co.in \\ P. Kalyana Sundaram \\ Associate Directior \\ IGCAR, Kalpakkam
}

\author{
N. Manoharan \\ Prof. \& Dean \\ Sathyabama University Jeppiaar Nagar \\ Old Mamallapuram Road, Chennai 119 \\ indiamano123@yahoo.com
}

\author{
B. Venkataraman \\ Head, QAD, IGCAR, \\ Kalpakkam \\ bvenkat@igcar.gov.in
}

\author{
Baldev Raj \\ Director, IGCAR, \\ Kalpakkam
}

\begin{abstract}
The quality of welded steel structures play an important role in determining the reliability of a building. Weld quality is affected by Incomplete Penetration, which is a most commonly occurring defect in welds. An automated adaptive welding system if developed can correct the deviation in the welding current online so as to adjust the depth of Penetration to provide defect free welds. This system requires an on-line weld-monitoring sensor, efficient image processing algorithm for defect identification and neurofuzzy control software for correlating the defect characteristics with deviations in physical parameters. Infrared Thermography is the best-suited sensor for on-line weld monitoring and continuous assessment of welds. Incomplete penetration affects the hot spot of the thermograph and hence hot spot quantification describes the defect effectively. Three different algorithms namely conventional algorithm, region-growing algorithm and Euclidean distance based color image segmentation algorithm are developed for hot spot quantification. The paper compares the effectiveness and suitability of these algorithms for on-line weld monitoring.
\end{abstract}

\section{KEYWORDS}

Thermographs, Incomplete Penetration, Region Growing, Color Segmentation

\section{INTRODUCTION}

Gas Tungsten Arc Welding (GTAW) commonly referred, as Tungsten Inert Gas (TIG) welding is best suited for precision welding of steel structures. It is an arc welding process wherein coalescence is produced by heating the job with an electric arc struck between a Tungsten electrode and the job. A shielding gas is used to avoid atmospheric contamination of the molten weld pool. In spite of the numerous advances in development of automatic weld manufacturing equipments, failures do occur and weld is still considered to be the weakest portion. Incomplete Penetration affects the quality of weld ands is a serious defect. Conventionally, the quality of the 
weld is ascertained only after the welding has been completed through the use of Non Destructive Testing (NDT) such as ultrasonic or radiography. Since each of these techniques is applied only after the welding is completed, a lot of time, material and manpower are wasted before one comes to know about the soundness of the weld.

These limitations can be overcome if the weld is continuously monitored in real time for the assessment of defects and their automatic elimination by on-line control of the welding parameters. It is achieved through Adaptive welding techniques, which involve suitable sensors, image processing algorithms for defect feature extraction, extracting relationship between the defect features and physical parameters responsible for the defect and neuro fuzzy control software for obtaining the deviations in the weld physical parameters.

Infrared thermography is the best-suited sensor for on-line weld monitoring as the sensor measures the temperature variations in the weld pool during the welding process. Numerous groups worldwide have used Infrared investigation techniques in the inspection of subsurface defects and features, thermo physical properties, coating thickness and hidden structures. Thermographs are used to the control of welding process problems, such as arc misalignments [1]. Variations in plate thickness, shielding gas composition and minor element content causes weld geometry changes. These parameter deviations are detected from temperature gradients obtained from infrared data [2]. Infrared sensors are used for on-line weld geometry monitoring and control. Infrared thermography is the widely used method for NonDestructive Testing. Thermography offers noncontact, wide area detection of subsurface defects. Different passive and active thermographic techniques are used for defect detection. Active techniques include Pulse thermography, Lockin thermography, Pulsed phase thermography and vibrothermography [3-5]. Infrared sensors are best suited for weld quality detection as the perturbations that arise due to variations in arc positioning, heat input and the presence of contaminants distinctly manifests itself as differences in the spatial and temporal surface temperature distributions. Hence image analysis techniques can be developed to quantify the changes in the temperature distribution there by enabling adaptive welding techniques for automated weld control [6]. Quantification of thermographs is achieved by image processing algorithm through histogram equalization, image segmentation and morphological image processing. These features extracted from the algorithm are then used for on-line weld monitoring to produce defect free welds [7].

After acquiring thermal images, features corresponding to weld defects are extracted. These feature vectors are related to the corresponding deviations in physical parameters responsible for the defect. With this mapping, the respective physical parameter is then controlled to produce defect free welds. This paper proposes three different image-processing algorithms for hot spot quantification. The paper also compares the performance of these algorithms and examines the suitability of these algorithms for on-line weld monitoring.

\section{THERMOGRAPHS DEPICTING LACK OF PENETRATION}

Incomplete Penetration occurs when penetration of the weld metal into the joint is insufficient compared to what is specified for the joint according to the welding symbol. It is caused by too low welding current or too high welding speed or incorrect joint geometry. It is a serious defect as it can contribute to failure as stress raisers and least resistant path.

During the welding process, the high temperatures associated with the arc and appropriate thermo physical properties such as thermal diffusivity cause strong spatial temperature gradients to occur in the weld pool. The thermal maps produced by infrared thermal imaging instruments are called thermographs. Thermograph is defined as a $2 \mathrm{D}$ radiance function $\mathrm{g}(\mathrm{x}, \mathrm{y})$, where $\mathrm{x}$ and $\mathrm{y}$ denote spatial coordinates and the value of $g$ at any point is proportional to the radiance or energy emitted from the scene at that location. Traditionally, low intensities are represented by dark shades and high intensities by bright shades. With the decrease in degree of penetration or increase in Lack of Penetration, the area, major axis length and minor axis length of the hotspot also decreases. Thermographs for three different depths of 
penetration namely $100 \%, 80 \%$ and $60 \%$ are shown in Figure 1, Figure 2 and Figure 3.

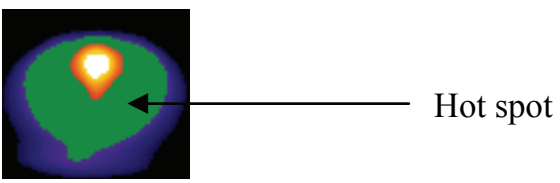

Figure 1 Thermograph Depicting 100\% Penetration

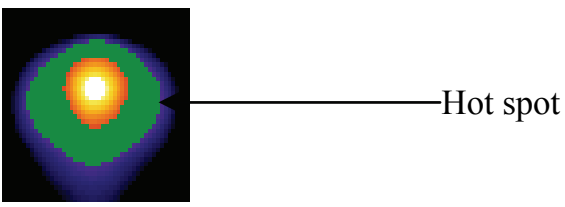

Figure 2 Thermograph Depicting 80\% Penetration

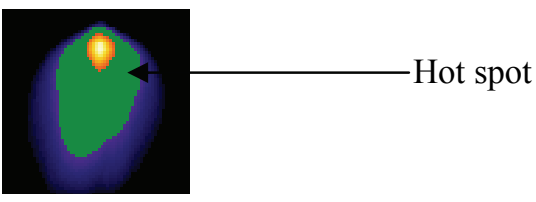

Figure 3 Thermograph Depicting 60\% Penetration

\section{DIGITAL IMAGE PROCESSING ALGORITHMS}

A digital image is defined as a two-dimensional function, $f(x, y)$ where $x$ and $y$ are finite values representing spatial co-ordinates, and the amplitude of $\mathrm{f}$ at any pair of co-ordinates $(\mathrm{x}, \mathrm{y})$ is called the intensity or gray level of the image at that point. $F$ is also a finite quantity. These elements are referred as pixels. Developing suitable image processing algorithms identifies the region of interest.

\subsection{Conventional Image Processing Algorithm}

The developed algorithm involves image segmentation through edge detection, followed by dilation, region filling and erosion. Segmentation subdivides an image into its constituent regions or objects. The level to which the subdivision is carried out depends on the problem being solved. Edges of the hotspot region are obtained by using Sobel masks. From the edge-detected image, the hotspot is obtained through morphological image processing.

Mathematical morphology is for extracting image components that are useful in the representation and description of region shape such as boundaries, skeletons etc. It involves dilation, region filling and erosion. Dilation is for bridging the gap between the pixels in an image. With $\mathrm{A}$ and $B$ as sets in $Z^{2}$, the dilation of $A$ by $B$ is

$\mathrm{A}+\mathrm{B}=\left\{\mathrm{z} \backslash\left(\mathrm{B}^{\wedge}\right)_{\mathrm{z}} \mathrm{nA} \neq \Phi\right\}$

Where $\mathrm{B}$ is the structuring element. The structuring element chosen is 'line'. Region filling makes all the pixels in the bounded regions as white thereby differentiating it from the background. The procedure to fill the region with 1 's is

$\mathrm{Xk}=(\mathrm{Xk}-1+\mathrm{B}) \mathrm{nA}^{\mathrm{c}}$

Where $\mathrm{k}=1,2,3 \ldots$ And $\mathrm{B}$ is the symmetric structuring element and $\mathrm{X}_{0}=\mathrm{p}$, where $\mathrm{p}$ is the point inside the boundary. Structuring element chosen is 'holes'. Erosion aims at removing the irrelevant details in an image.

With $A$ and $B$ as sets in $Z^{2}$, the erosion of $A$ by $B$ is

$A-B=\left\{z \backslash(B) z C \_A\right\}$

$\mathrm{B}$ is the structuring element. The structuring element chosen is diamond.

\subsection{Region Growing Algorithm}

Region growing algorithm is an algorithm that appends pixels or sub regions into larger regions based on predefined criteria. Hence the region of interest i.e. the weld defect is obtained directly through similarity detection. The algorithm involves selecting a seed pixel, which is the representative pixel of the region of interest. The seed pixel chosen is that whose intensity is eth median of pixel intensities in the region of interest. All pixels with nearly same intensities are grouped together. Grouping nearly similar pixels is achieved by selecting a threshold value. The selection of similarity criteria is dependent not only on the threshold but also on connectivity. Connectivity when considered prevents meaningless segmentation. 


\subsection{Euclidean Distance Based Color Image Segmentation}

Color is a powerful descriptor that simplifies object identification and extraction from a thermograph. Of the various color models, RGB color model is considered for further processing of the image. In the RGB color model, each color appears in its primary spectral components of red, Green and blue. Each RGB color pixel is a triplet of values namely Red, Green and Blue. Segmentation in color domain is based on similarity detection rather than discontinuity based.

The algorithm involves selecting an estimate of the average color that is to be segmented. Classifying each RGB pixel in the image as having the specified average color or not. I.e. similar pixels are grouped together. Euclidean distance is chosen as the measuring parameter. Let the average pixel chosen be represented as ' $a$ '. Any image pixel ' $z$ ' is said to be similar to ' $a$ ' if the Euclidean distance between them is less than a specified threshold $\mathrm{D}_{0}$. Choosing $\mathrm{D}_{0}$ is dependent on the defect that is to be classified. For all the thermographs of same defect, the value of $\mathrm{D}_{0}$ is same, hence making this algorithm image independent and parameter independent. The Euclidean distance between ' $\mathrm{z}$ ' and ' $a$ ' is

$\mathrm{D}(\mathrm{z}, \mathrm{a})=\left[\left(\mathrm{z}_{\mathrm{R}}-\mathrm{a}_{\mathrm{R}}\right)^{2}+\left(\mathrm{z}_{\mathrm{G}}-\mathrm{a}_{\mathrm{G}}\right)^{2}+\left(\mathrm{z}_{\mathrm{B}}-\mathrm{a}_{\mathrm{B}}\right)^{2}\right]^{1 / 2}$

Where the subscripts $R, G$ and $B$ denote the RGB components of vector ' $a$ ' and ' $z$ '. The extracted defects are then described quantitatively using feature vectors. The feature vectors used for description are major axis length, minor axis length and area.

\section{RESULTS AND DISCUSSION}

The hotspot isolated thermographs for three different depths of Penetration through conventional algorithm; region growing algorithm and Euclidean distance based color image segmentation are as shown in Fig. 4, Fig.5 and Fig. 6 . respectively.

The performance of these algorithms in terms of accuracy, time consumption, parameter dependency and image specificity are compared in Table 1.
From the table it is clear that the area, major axis length and minor axis length are nearly same. Choosing suitable threshold and average pixels in region growing and color segmentation algorithms can further reduce the deviation. The conventional algorithm is strongly dependent on the parameters namely filter and size of the filter chosen for edge detection, structuring elements and its size chosen for morphological processing. Hence these algorithms cannot be standardized fro a particular defect. Different programs (with different structuring elements) are to be written for images even of same defect.

Region growing and Euclidean algorithms require standard parameters for all the images of same defect. These algorithms can be standardized and can be considered for on-line weld monitoring. However the time taken by Euclidean algorithm is more when compared to region growing.

\section{CONCLUSION AND FUTURE WORK}

All the three algorithms are effective in hotspot identification and quantification. However due to its parameter dependency and different programs for different images of the same defect conventional algorithm is not suited fro on-line weld monitoring. Though region growing and Euclidean distance based algorithm can be standardized for a defect, due to less time consumption the Region Growing algorithm is best suited for on-line weld monitoring.

Wavelet based algorithm may also be considered due to its multiresolution analysis may detect more number of defects on a thermograph. But time taken by this algorithm will be more than any of the developed image processing algorithms. 


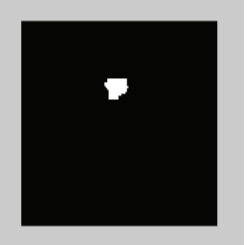

Figure 4a (100\% depth)

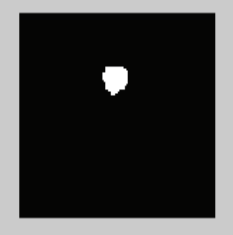

Figure 5a (100\% depth)

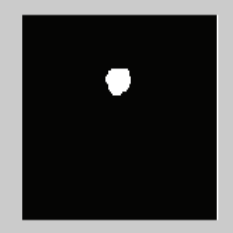

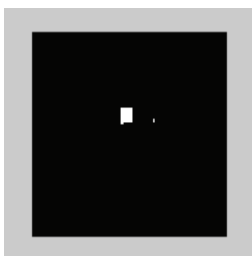

Figure 4b (80\% depth) Figure 4c (60\% depth)

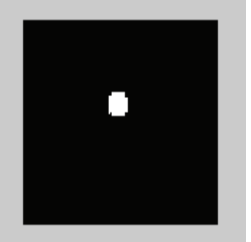

Figure 5b (80\% depth) Figure 5c (60\% depth)

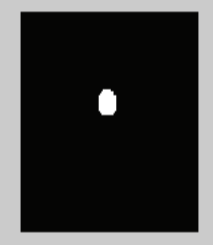

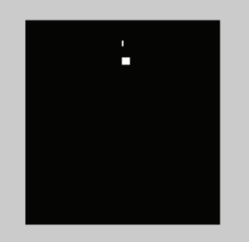
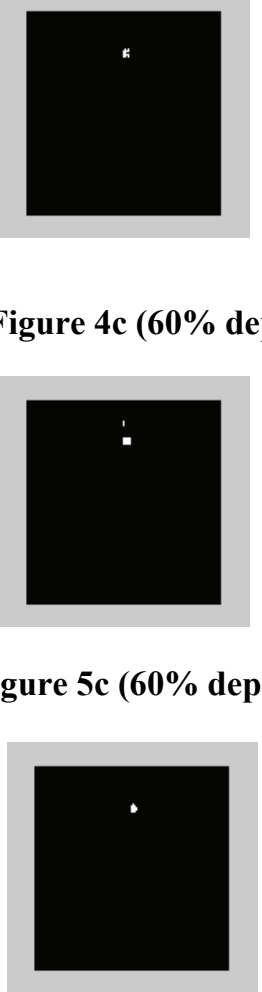

Figure 6a (100\% depth) Figure $6 \mathrm{~b}(80 \%$ depth) Figure $6 \mathrm{c}(60 \%$ depth)

Table 1 Performance Evaluation of Algorithms (Comparison)

\begin{tabular}{|c|c|c|c|c|c|c|c|c|c|c|}
\hline \multicolumn{2}{|c|}{ Parameters/Algorithm } & \multicolumn{3}{|l|}{ Conventional } & \multicolumn{3}{|c|}{ Region Growing } & \multicolumn{3}{|c|}{ Euclidean Color } \\
\hline \multirow{4}{*}{$\begin{array}{c}\text { Accuracy of } \\
\text { Result }\end{array}$} & $\begin{array}{l}\text { Depth/ } \\
\text { Feature } \\
\text { Vector }\end{array}$ & $100 \%$ & $80 \%$ & $60 \%$ & $100 \%$ & $80 \%$ & $60 \%$ & $100 \%$ & $80 \%$ & $60 \%$ \\
\hline & $\begin{array}{l}\text { Major Axis } \\
\text { Length (in } \\
\mathrm{cm} .)\end{array}$ & 0.4879 & 0.2948 & 0.1732 & 0.4245 & 0.3169 & 0.1579 & 0.528 & 0.418 & 0.126 \\
\hline & $\begin{array}{l}\text { Minor Axis } \\
\text { Length (in } \\
\mathrm{cm} . \text { ) }\end{array}$ & 0.3463 & 0.2731 & 0.1385 & 0.3258 & 0.3039 & 0.1325 & 0.432 & 0.409 & 0.110 \\
\hline & $\begin{array}{c}\text { Area (in sq. } \\
\mathrm{cm})\end{array}$ & 0.1242 & 0.0594 & 0.018 & 0.1053 & 0.0738 & 0.0153 & 0.176 & 0.133 & 0.009 \\
\hline $\begin{array}{l}\text { Time Taken } \\
\text { (Pentium } \\
\text { IV, } 2.4 \mathrm{GHZ} \\
\text { processor) }\end{array}$ & $\begin{array}{l}\text { Time taken } \\
\text { for execution } \\
\text { (Seconds) }\end{array}$ & 0.4840 & 0.6250 & 0.7040 & 0.2970 & 0.2810 & 0.3100 & 0.4060 & 0.4690 & 0.4530 \\
\hline \multirow{4}{*}{$\begin{array}{c}\text { Parameter } \\
\text { Dependency }\end{array}$} & $\begin{array}{c}\text { Image } \\
\text { Segmentation }\end{array}$ & $\begin{array}{c}\text { Sobel filter } \\
\text { Threshold = } \\
\text { graythreshold } \\
* 0.35\end{array}$ & $\begin{array}{c}\text { Sobel filter } \\
\text { Threshold = } \\
\text { graythreshold } \\
* 0.15\end{array}$ & $\begin{array}{c}\text { Sobel filter } \\
\text { Threshold = } \\
\text { graythreshold } \\
*_{0.15}\end{array}$ & \multicolumn{3}{|c|}{$\begin{array}{c}\text { Seed pixel, intensity }=0.98 \\
\text { Threshold }=0.04\end{array}$} & \multicolumn{3}{|c|}{$\begin{array}{l}\text { Average pixel intensity } \\
(\mathrm{R}=0.9785, \mathrm{G}=0.9785 \\
\mathrm{B}=0.9785)\end{array}$} \\
\hline & Dilation & $\begin{array}{l}\text { Line (2 } \\
\text { pixels) }\end{array}$ & line ( 1 pixel) & No dilation & - & - & - & - & - & - \\
\hline & Region filling & holes & holes & holes & - & - & - & - & - & - \\
\hline & Erosion & $\begin{array}{c}\text { Square } \\
\text { Size }=4 \\
\text { Done once }\end{array}$ & $\begin{array}{c}\text { Square } \\
\text { Size }=4 \\
\text { Done twice }\end{array}$ & $\begin{array}{c}\text { Square } \\
\text { Size }=2 \\
\text { three times }\end{array}$ & - & - & - & - & - & - \\
\hline
\end{tabular}




\section{REFERENCES}

[1] Khan.M.A, Madsen. N.H., Goodling. G.S. and Chin. B.A., (1986) "Infrared Thermography as a Control for the Welding Process", optical Engineering, Vol.25, pp.799-805.

[2] Banarjee. P., Govardhan. S., Wikle. H.C., Liu. J.Y. and Chin. B.A., (1995) "Infrared Sensing for On-Line Weld Geometry Monitoring and Control", Journal of Engineering for Industry, Vol.117, pp.323-330.

[3] Ibarra-Castanedo. C., Galmiche. F., Darabi. A., Pilla. M., Klein. M., Ziadi. A., Vallerand. S., Pelletier. J.-F., Maldague. X., (2003) "Thermographic nondestructive evaluation: overview of recent progress", SPIE Proc. Thermosense XXV (SPIE: Society of PhotoOptical Instrumentation Engineers), 5073: 450459, Orlando, X. Maldague, A. Rozlosnik eds., FL.
[4] Maldague. X., (2002)“Introduction to NDT by Active Infrared Thermography," Materials Evaluation, 6[9]: $1060-1073$.

[5] Maldague. X.,, (2000) "Applications of Infrared Thermography in NonDestructive Evaluation," Trends in Optical Nondestructive Testing (invited chapter), Pramod Rastogi ed., pp. 591- 609.

[6] Nagarajan, S., Chen. W.H. and Chin. B.A., (1989) "Infrared Sensing for Adaptive Arc Welding", Welding Journal, Vol.68, pp.462s466s.

[7] Venkataraman. B., Baldev Raj and Menaka. M. (2005), "Online Infrared Detection of Inclusions and Lack of Penetration during Welding”, Materials Evaluation, pp. 933-937 